\title{
MULTI-LEVEL FILTERED EVENT STUDIES: A NEW APPROACH TO EVENT ANALYSIS
}

\author{
*Rifat GORENER \\ **Ding Li \\ ***John R. NORSWORTHY \\ *Roosevelt University, USA \\ **Northern State University, USA \\ ***Rensselaer Polytechnic Institute, USA
}

\begin{abstract}
This paper demonstrates the concept that monitoring stock price performance can identify significant events in publicly traded companies. The approach uses two types of filtering for stock price movements in a procedure that inverts the conventional event study methodology. "Noise" - market effects and small transient perturbations - are filtered from stock price movements in a two-stage process. The first filter is based on a model (the 4-State Model) derived from the conventional market model or CAPM. The second is a wavelets filter from electronic engineering that concentrates significant stock price movements by aggregating them into event study-type windows. While the usual fundamental analysis seeks ideally to identify potential breakthroughs before they occur, as a practical matter, only a limited number of companies can be analyzed at the level required to do so. This two-filter inverse event study procedure is more in the chartist tradition in that it seeks to identify unusual stock price movements when they occur. The filtering procedure, when followed up with information from the financial and technology press, the individual companies, and other sources, can assist in identifying financially significant events from a stream of historical stock price data. The inverse event study can identify a variety of events for further screening. For example, real time monitoring of data feeds from foreign stock exchanges in the search for emerging investment opportunities is a potential application of the approach described and demonstrated here.
\end{abstract}

Key Words: Event Study, 4State Model, Wavelets

\section{INTRODUCTION}

Methodology introduced here demonstrates the concept that monitoring stock price performance can identify significant events in publicly traded companies especially when the type of the economic event and the time of occurrence of the economic event are unknown. The approach uses two types of filtering for stock price movements in a procedure that inverts the conventional event study methodology. "Noise" - market effects and small transient perturbations - are filtered from stock price movements in a two-stage process. The first filter is based on a model (the 4-State Model) derived from the conventional market model or CAPM. This filter removes the effects of market-wide movements the individual stock price, based on both conditional financial $\beta$ s based on psychological considerations. The second is a wavelets filter from electronic engineering that concentrates significant stock price movements by aggregating them into event study-type windows. The procedure is designed to be useful for monitoring the performances of small publicly traded companies on historical or a real time basis. While the usual fundamental analysis seeks ideally to identify potential breakthroughs before they occur, as a practical matter, only a limited number of companies can be analyzed at the level required to do so. This two-filter inverse event study procedure is more in the chartist tradition in that it seeks to identify unusual stock price movements when they occur. The filtering procedure, when followed up with information from the financial and technology press, the individual companies, and other sources, can assist in identifying financially significant events from a stream of historical stock price data. This is especially relevant for small and foreign publicly traded companies where only scant information reaches the "radar screen": the inverse event study can identify a variety of events 
for further screening. For example, real time monitoring of data feeds from foreign stock exchanges in the search for emerging investment opportunities is a potential application of the approach described and demonstrated here.

\section{LITERATURE REVIEW \\ Conventional Event Study Literature}

Traditional event analysis starts with the selection of exactly what is the event of interest. This initial step of the study involves determining what constitutes the event of interest, when it is considered to happen, how long it takes to occur, and finally the length of the "event window", the period the asset will be observed after the event occurs.

Abnormal returns tests have generally consisted of three steps: (1) estimating the market model parameters over an estimation period, (2) estimating abnormal returns for periods surrounding the hypothesized event date (event window) using the parameter estimates from step (1), and (3) testing some form of the hypothesis that the abnormal returns are not significant. The selection of the estimation and event window is largely arbitrary.

Event studies have been around quite a long time. Dolley's price effects of stock splits (1933), can viewed as the first event study in the history. From the 1930s to the 1960s, several researchers, e.g. Myers and Bakay (1948), Barker (1956, 1957, and 1958) and Ashley (1962), improved event study technique by addressing limitations such as removing the general market effect and separating out confounding events (Campbell, Lo and MacKinlay (1997), p. 150.).

Ideally, it would be correct to refer to the Fama, Fisher, Jensen and Roll (1969) paper on dividend splits as the base model of event study of today. Event studies have since been done on many topics, usually to provide evidence that the market incorporates new information very quickly and usually correctly

There are some studies showing modifications of the basic methodology of the Fama et al. study improving the statistical assumptions and elaborating the hypotheses testing. Brown and Warner (1980, 1985) are important milestones of this type. The time line of the conventional event study is shown on Figure 1.

Figure 1. Time Line for a Traditional Event Study

Another class of tests, outlier tests, does not require an event window. The outlier tests can be applied to abnormal returns testing. Both the traditional abnormal return and outlier tests can identify significant abnormal returns as in Howe and Pope (1996). However, compared with the traditional test, the implementation of the outlier test used in the present study classifies a much smaller proportion of the observations as outliers. That is principally because the 4-State model is more successful in removing market-related movements in the returns of the target asset.

\section{Inverse Event Studies}

Finance as well as business science generally focuses on shareholder value as the objective of the enterprise. Market prices reflect the investors' expectations of future performance, which is summarized in shareholder value. This paper identifies events that correspond to changes in investors' expectations of the firm's returns. Event studies are most commonly used to examine the direction and magnitude 
of security price reactions to various information sets. This paper, in contrast, identifies significant events when the type and time of occurrence of the event unknown.

The classical event study proceeds from the known event to measure its effects on the stock price after a single filtering stage. Our two level filter approach proceeds differently: it seeks to determine whether significant events have occurred anywhere in a given time series. When the event or the date of occurrence is unknown we apply a dual filter procedure to identify unusual movements in stock price by searching for outliers in filtered asset returns. The technique has two stages of filtering: 4State Asset Pricing Model and wavelet sub-band compression.

From the data analysis perspective, filtering stock prices is a technique to identify events associated with significant price changes when the dates of the price changes are unknown. That is, it may be regarded as a form of data mining. The proposed approach in this paper, which is denoted the dual filter inverse event study (DFIES) filters market and other non-company specific events from the outlying observations. ${ }^{1}$ The core idea is that sampling successively lower frequencies by the wavelets transform concentrates the returns information into successively larger psuedo-event windows. The coefficients of the first wavelets transform, or "down sample" corresponds to a two-day window, the second down sample to a four day window, and the third to an eight day window. The intuition is therefore straightforward: more significant spurts in returns, positive and negative, will be identified in the higher order sets of coefficients, or down samples. The results may be sensitive to the starting date of the original time series, so that shifting the start date through the length of the largest window to be considered will tend to identify events whose effects, for some choices of start dates, could be spread over adjacent windows and their corresponding coefficients.

This DFIES is especially useful for identifying events related to the small size and foreign firms.

The DFIES procedure works as follows:

1. Filter out market effects by $4-$ State Model as a filter.

2. Aggregate adjacent returns into windows of varying length by wavelet sub-band compression.

3. Detect significant price changes (SPC) by outlier analysis of the filtered returns.

Then based on the times of occurrence of the SPCs, the investigator can look for causes of price change in the appropriate media such as financial news wires, company news releases, etc. The flow diagram of the suggested DFIES technique is shown in Figure 2.

Figure 2: The Flow of the Dual Filter Inverse Event Study

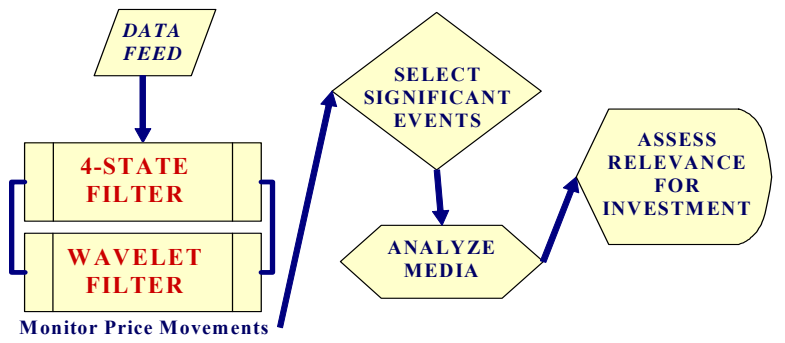

There are multiple sources of stock price movements that reflect general market forces, as well as industry-wide movements - called "contagion effects" First stage of the analysis is to apply the 4 - State Model (Norsworthy et al, 2001), which reduces the variation in the stock return by eliminating market effect. This procedure is far more effective than the usual CAPM or market model. 4-State Asset Pricing Model filters out the effects of the market-wide movements on the individual stock prices, based on both conventional financial and psychological considerations.

\footnotetext{
${ }^{1}$ For particular industries, such as semiconductors in the United States where there appears to be a great deal of contagion, an industry-based filter based on the 4-State model may be preferable to a market based 4-State model demonstrated here.
} 


\section{METHODOLOGY}

\section{The 4-State Filter}

The 4-State model is described and tested extensively in Norsworthy et al. (2000). It is designed for high frequency data, and is applied to daily returns for 100 companies for the period 1984-1999. Essentially it consists of a state-dependent model of asset returns parallel to the conventional market model (Eq.1):

$r_{A t}=\alpha+\beta\left(r_{M t}\right)+e_{t}$

By partitioning the observations into four cases depending on the state of the market returns and asset returns, four "states" of the market are determined, as shown in Table 1.

the Table 1. Partitioning Decision Rules by Signs of $\mathbf{r}_{A}$ and $\mathbf{r}_{M}$

\begin{tabular}{|c|c|c|}
\hline Partition or State & Sign of Asset Return & Sign of Market Return \\
\hline 1 & $\mathrm{r}_{\mathrm{A}} \geq 0$ & $\mathrm{r}_{\mathrm{M}} \geq 0$ \\
\hline 2 & $\mathrm{r}_{\mathrm{A}}<0$ & $\mathrm{r}_{\mathrm{M}} \geq 0$ \\
\hline 3 & $\mathrm{r}_{\mathrm{A}}<0$ & $\mathrm{r}_{\mathrm{M}}<0$ \\
\hline 4 & $\mathrm{r}_{\mathrm{A}} \geq 0$ & $\mathrm{r}_{\mathrm{M}}<0$ \\
\hline
\end{tabular}

Observations are partitioned according to the signs of the asset and market returns.

These four partitions define the four states where the coefficients are estimated combined in a single representation

$$
r_{A t}=\sum_{i} \alpha_{i}+\sum_{i} \beta_{i} r_{i M t}+e_{t} \quad i=1, \ldots, 4
$$

The 4-State model substantially out-performs the market model, especially for smaller firms, as Table 2 shows.

\section{Table 2. Average Explanatory Power of Market and 4-State Models by Size,} 1984-98

\begin{tabular}{|l|c|c|}
\hline \multicolumn{1}{|c|}{ Panel } & 4-State Model & Market Model \\
\hline D-J Industrials & 0.7319 & 0.3723 \\
\hline S\&P Mid Cap & 0.6109 & 0.0955 \\
\hline S\&P Small Cap & 0.6197 & 0.1024 \\
\hline Total Sample & 0.6508 & 0.1646 \\
\hline
\end{tabular}

The table shows the average explanatory power of alternative asset pricing models measured by adjusted $\mathrm{R}^{2}$ coefficients for three size classes and the whole panel of 100 companies for the 15 -year period, 1984-1998. The models were estimated by OLS with adjustment for heteroskedasticity.

The advantage of the 4-State over the conventional model persists through time, especially in more recent years. 
Table 3. Effects of Outlier, Market Model and 4-State Model Filters

\begin{tabular}{|l|r|r|r|r|}
\hline & Returns & Deviations & $\begin{array}{c}\text { Base } \\
\text { Model }\end{array}$ & $\begin{array}{r}\text { 4-State } \\
\text { Model }\end{array}$ \\
\hline Mean & 0.00186 & 0 & 0 & 0 \\
\hline Variance & 0.00093 & 0.00093 & 0.00075 & 0.00031 \\
\hline Skew & 0.16204 & 0.16204 & 0.17342 & 0.01476 \\
\hline Kurtosis & 1.80777 & 1.80777 & 2.62865 & 4.98858 \\
\hline
\end{tabular}

\section{The Wavelets Filter: A Brief Introduction to Wavelet Analysis ${ }^{2}$}

Wavelet analysis is a new development in applied mathematics about ten years in duration. Brief historical reviews of wavelets can be found in Meyer (1993) and Graps (1995). Y. Meyer, I. Daubechies, S.Mallat and others developed the theory of wavelets in the late 1980's. ${ }^{3}$ Wavelet analysis has been applied to many situations with favorable results. Wavelet analysis has remarkable impact mainly on three fields, signal processing (Donoho and Johnstone, 1998), image analysis, and data compression (Bradley, Brislawn et al., 1993).

Generally speaking, wavelet analysis is a refinement of Fourier analysis. The Fourier Transform (FT) processes the raw signal (a time series) by using a mathematical transformation, which transforms the signal from time domain into frequency spectrum. The processed signal tells us how many frequencies and how much (energy) of each frequency exists in the raw signal, but it does not give us the time information (where a particular frequency appears in the time domain). If the signal is stationary, we don't need the "location" information, but in the real world most of our data sets are non-stationary.

The Windowed Fourier Transform (WFT) can locate the window of the data that are transformed in time. ${ }^{4}$ The WFT only transforms part of a signal and that segment of signal is small enough that we can assume that portion of signal is stationary. By using a particular window function and shifting the window along the time dimension of the signal we can localize the frequency in the signal, and we obtain a time-frequency representation of the signal. The transformation coefficients are the amplitudes of different frequencies at different times. But WFT has a problem, known as the resolution problem. The Heisenberg uncertainty principle states that we cannot know the exact time-frequency representation of a signal. We can know however the bands of frequencies associated with the time intervals in the signal. Here we must have a requirement on the width of the window function. The wavelet transformation is a solution to the problem.

The orthogonal wavelet series approximation to a time series $f(t)$ is given by (Eq. 3 )

$$
\left.f(t) \approx \sum_{k} s_{J, k} \phi_{J, k}(t)+\sum_{k} d_{J, k} \psi_{J, k}(t)+\sum_{k} d_{J-1, k} \psi_{J-1, k}(t)+\cdots+\sum_{k} d_{1, k} \psi_{1, k}(t) \quad \text { (Eq. } 3\right)
$$

$J$ is the number of levels (scales or frequencies), and $k$ ranges from 1 to the number of coefficients in the specified component. $\phi_{j, k}(t)$ and $\psi_{j, k}(t)$ are the approximating orthogonal wavelet functions given by (Eq. 4 \& 5)

$$
\begin{array}{ll}
\phi_{j, k}(t)=2^{-j / 2} \phi\left(\frac{t-2^{j} k}{2^{j}}\right) & j=1 \text { to } J \\
\psi_{j, k}(t)=2^{-j / 2} \psi\left(\frac{t-2^{j} k}{2^{j}}\right) \quad j=1 \text { to } J
\end{array}
$$

\footnotetext{
${ }^{2}$ This section is taken largely from Norsworthy, Gorener and Li (2000).

${ }^{3}$ See Norsworthy et al. (2000) for these and some other references to the wavelets literature. B. B. Hubbard (1998) provides a readable and instructive account of the development of wavelets theory and its applications, as well as a guide to some of the deeper.

${ }^{4}$ The WFT, considered a landmark paper in the frequency analysis literature, is attributed to Denis Gabor (1946).
} 
The wavelet coefficients are given by (Eq. $6 \& 7$ )

$$
\begin{aligned}
& s_{J, k} \approx \int \phi_{J, k}(t) f(t) d t \\
& d_{j, k} \approx \int \psi_{j, k}(t) f(t) d t
\end{aligned}
$$

The most common application of wavelets is in signal processing. ${ }^{5}$ In this sense, a signal is a sequence of numerical measurements. In signal processing, the main or basic tasks are coding the signal (possibly compressing or encrypting it) and transmitting the signal. The objective of this process is to optimize the efficiencies of signal coding, transmitting, and reconstruction. Another emphasis of the wavelets literature of signal processing is denoising, i.e., extracting the true signal from the observations spoiled by noise. Wavelet analysis performed well in those applications. Data compression is another field in which wavelet analysis has impressive results. The purpose of data compression is to transform large data set into smaller data set, which contains the most important elements and can be reconstructed later with only a minimum of loss. FBI fingerprints storage is a success application of wavelets.

In statistical applications, wavelet analysis has both linear smoothing and nonlinear smoothing properties. Donoho (1993) developed the thresholding technique, a procedure of estimating an unknown signal from observed data by using the smoothing statistic properties of wavelets.

Applications to finance are perhaps best exemplified by the papers of Ramsey and his collaborators (for example, Ramsey and Lampart, 1998a and 1998b; Ramsey and Zhang, 1997).

\section{EMPRICAL RESULTS \\ The Demonstration Target Company: Amgen}

Amgen Corporation is selected as the target for the demonstration because it is well known. The concept behind the demonstration, however, is that the technique would be applied where information is less readily available: for small and/or foreign publicly traded companies. The two-stage filtering of data is applied to the daily prices of Amgen's common stock for 1996-1999 taken from CRSP. ${ }^{6}$ The effect of the filtering process is shown in Figure 3. The series E0 shows deviations of Amgen returns around the mean. ER is the returns series filtered by the 4-State model. The scales and the time domains in the two panels of Figure 3 are the same. The visual evidence for the effectiveness of the 4State filter is dramatic. The DFIES removes about two-thirds of the variance from the Amgen returns, while the market model removes less than one fourth. The important point is that much more of the asset return is explained by market return when the different states of the market faced by the decision-maker are taken into account, and thus the resulting time series is influenced relatively more than the original series by company-specific effects. (The CAPM and market model filters give almost identical residuals. This strong similarity is noted in some of our other work, e.g. Norsworthy et al, 2002). The price series is also shown in Figure 4.

\footnotetext{
${ }^{5}$ S-PLUS, which has good support for wavelet analysis as does Matlab, uses a fast pyramid algorithm to calculate the coefficients of the wavelet series approximation for the discrete signal $f_{1}, \ldots, f_{n}$ of finite length.

${ }^{6}$ CRSP: Center for Research in Securities Prices, University of Chicago School of Business.
} 
Figure 3. E0: Deviations of Returns from Mean

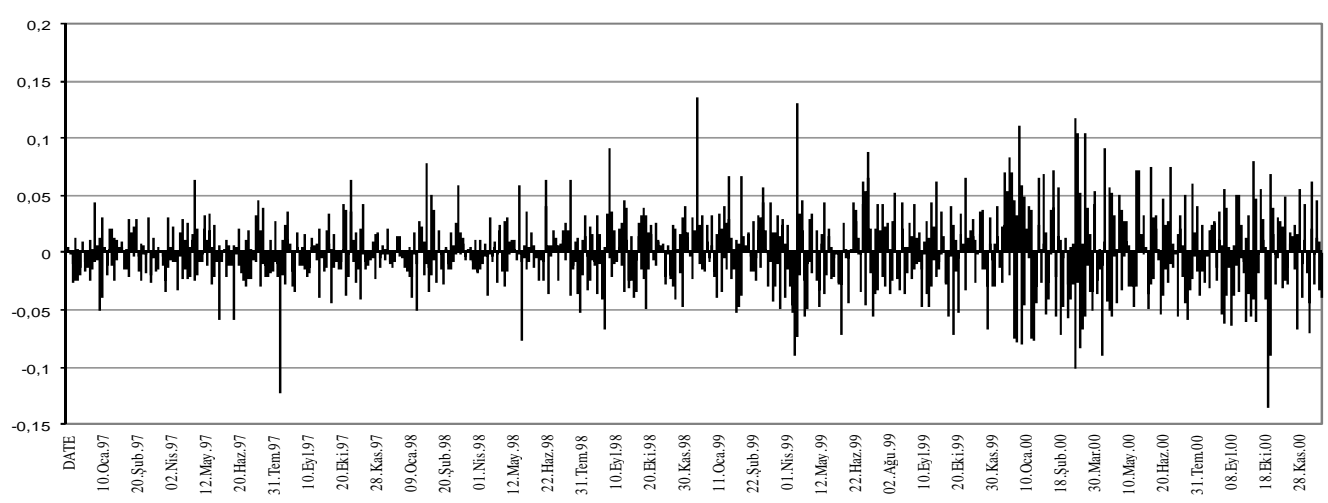

ER

4-State Model Reduces Deviation More

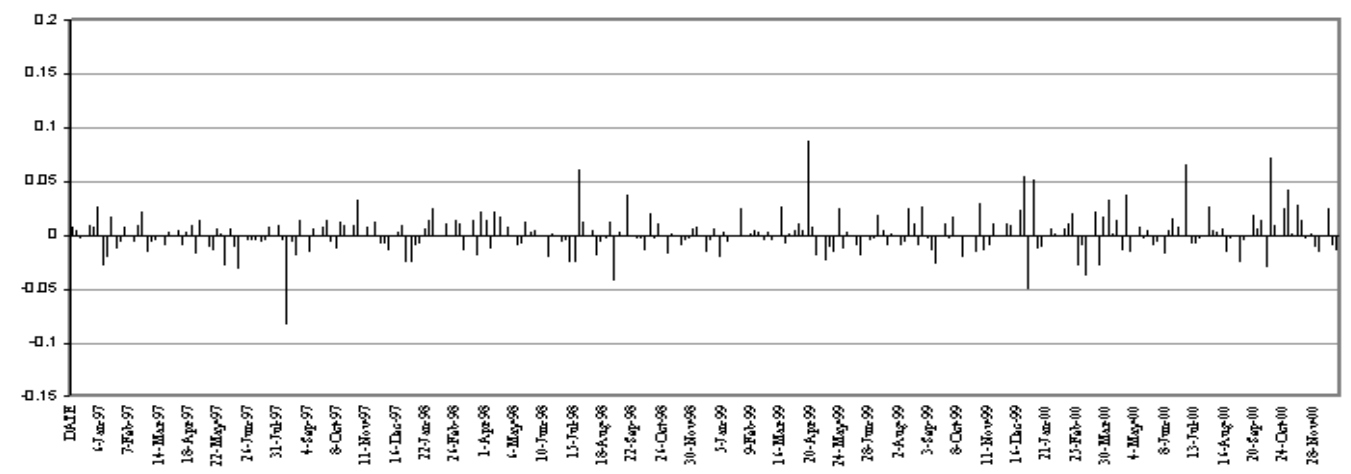

Figure 4. 1997-2000 Amgen Stock Price

STOCK PRICE: AMGN

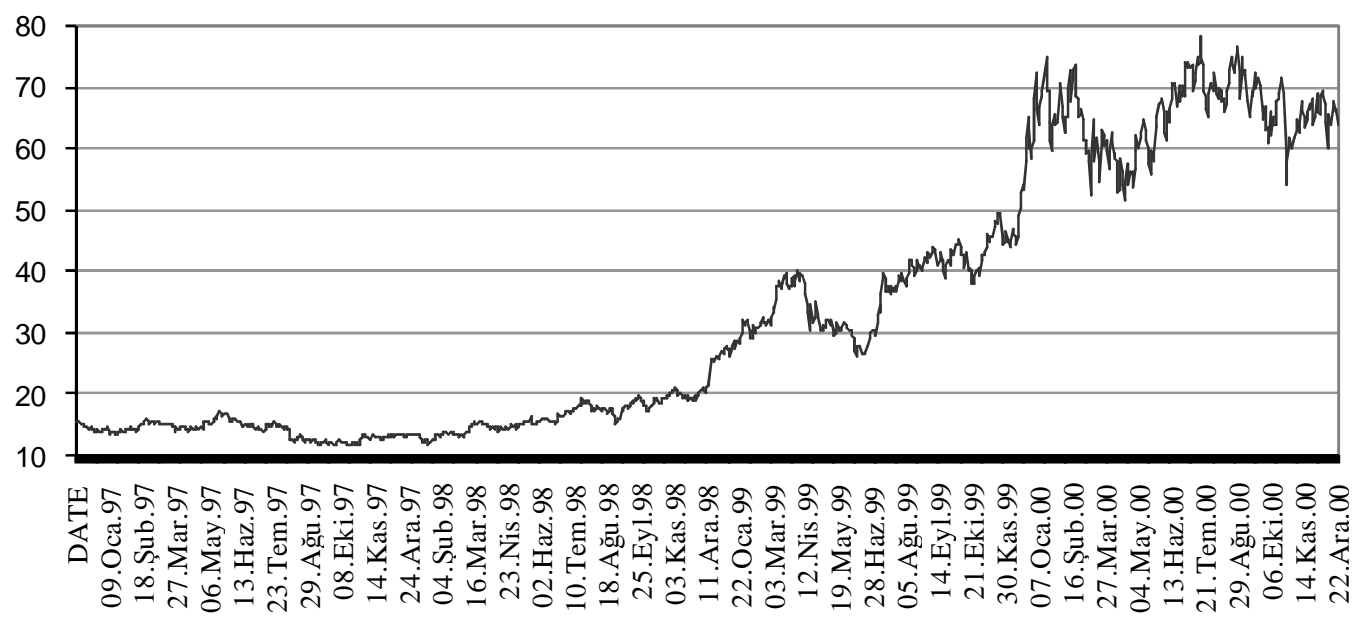

The effects of the wavelets filter, applied to the 4-State filtered returns, are shown Figure 5. The increasing window size for calculating returns concentrates the number of potentially significant occurrences, so that the last panel of Figure 5 identifies only a handful of events (event windows) for further examination. This concentration of price changes removes all but the most extreme events; moreover, the number of events that are selected for individual scrutiny is under the control of the investigator: the wavelets extraction process may be adapted to any window size. Corresponding hypothesis 
tests following the model for cumulative abnormal returns in Campbell, Lo and MacKinlay (1997) may be constructed based on the size of the wavelets window chosen.

Figure 5. Wavelets Filter Applied to Amgen Returns

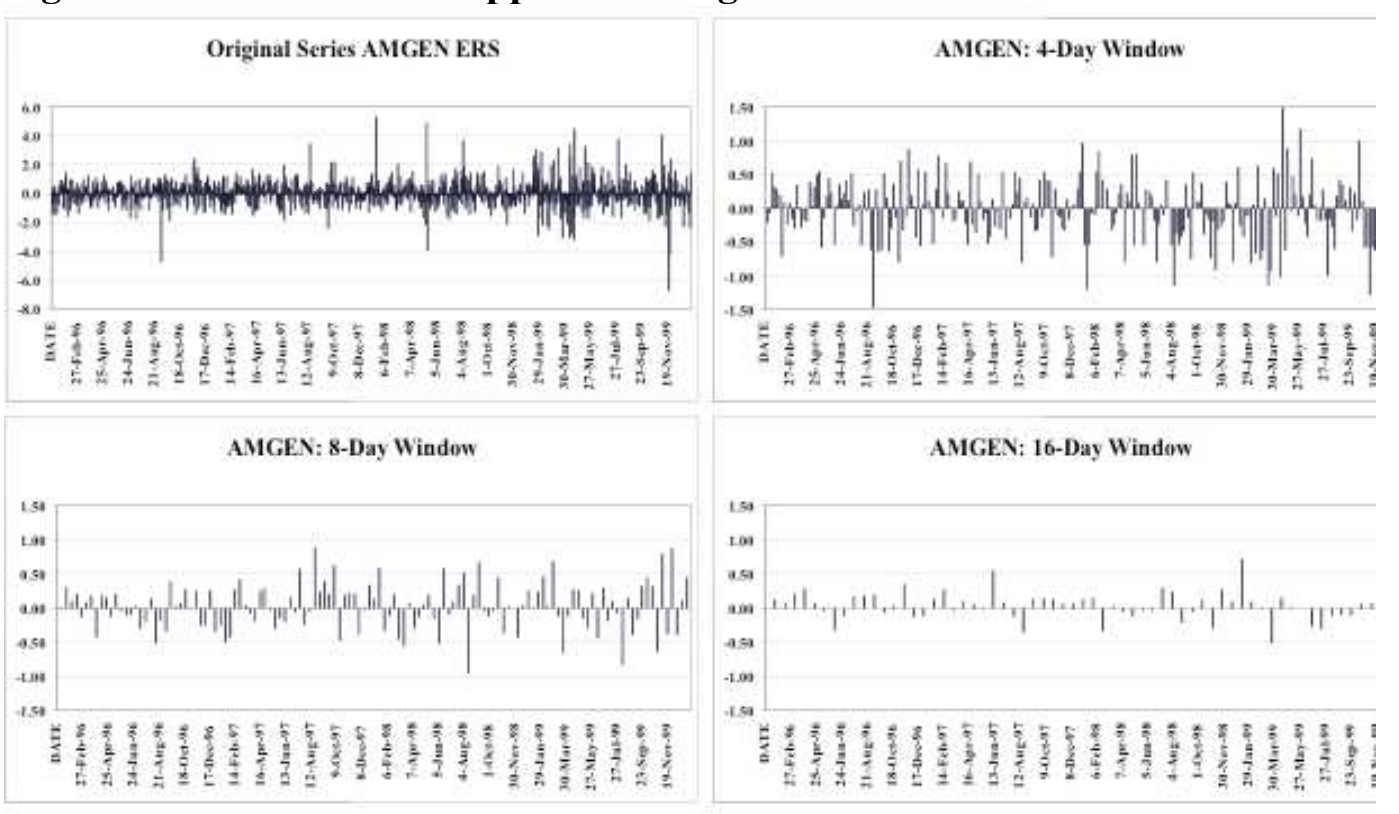

The last panel in Figure 5 shows the events that correspond to the spikes in twice-filtered returns. These descriptions of events were culled from the financial press after the significant event periods were determined from the filtering process.

The charts in the Appendix show the original returns after filtering by the 4-State Model, and the first three down-sampling operations, corresponding to windows of two, four, and eight days. There are nine additional companies that are analyzed by the dual filter process. We have not varied the start dates to search for more dominant windows, although this could readily be done. For each of the nine companies, the appendix charts show the effects of concentrating the returns information by successive down samples into lower frequency movements, which substantially improve the definition of short term trends. The removal of market-related effects at the outset, by applying the 4-State filter, increases the focus of the results on company-specific movements.

While the conventional wavelet down sampling pattern proceeds by powers of two, and thus omits windows of intermediate sizes, the decomposition may be modified to look at windows of all sizes, e.g., $2,3,4,5,6,7,8 \ldots$ trading days rather than $2,4,8 \ldots$ This modification increases the scope of the wavelets transform and thus its data analysis potential.

\section{CONCLUSION}

The demonstrations here show that the inverted event study approach, based on financial and wavelets filters, has potential as a data analysis tool for identifying significant financial events. Moreover, it represents an ideal fusion of finance and signal processing techniques that carries analysis well beyond the present scopes of either science. Finally, the approach has potential as a tool for identifying investment opportunities in small domestic and foreign companies that are publicly traded. 

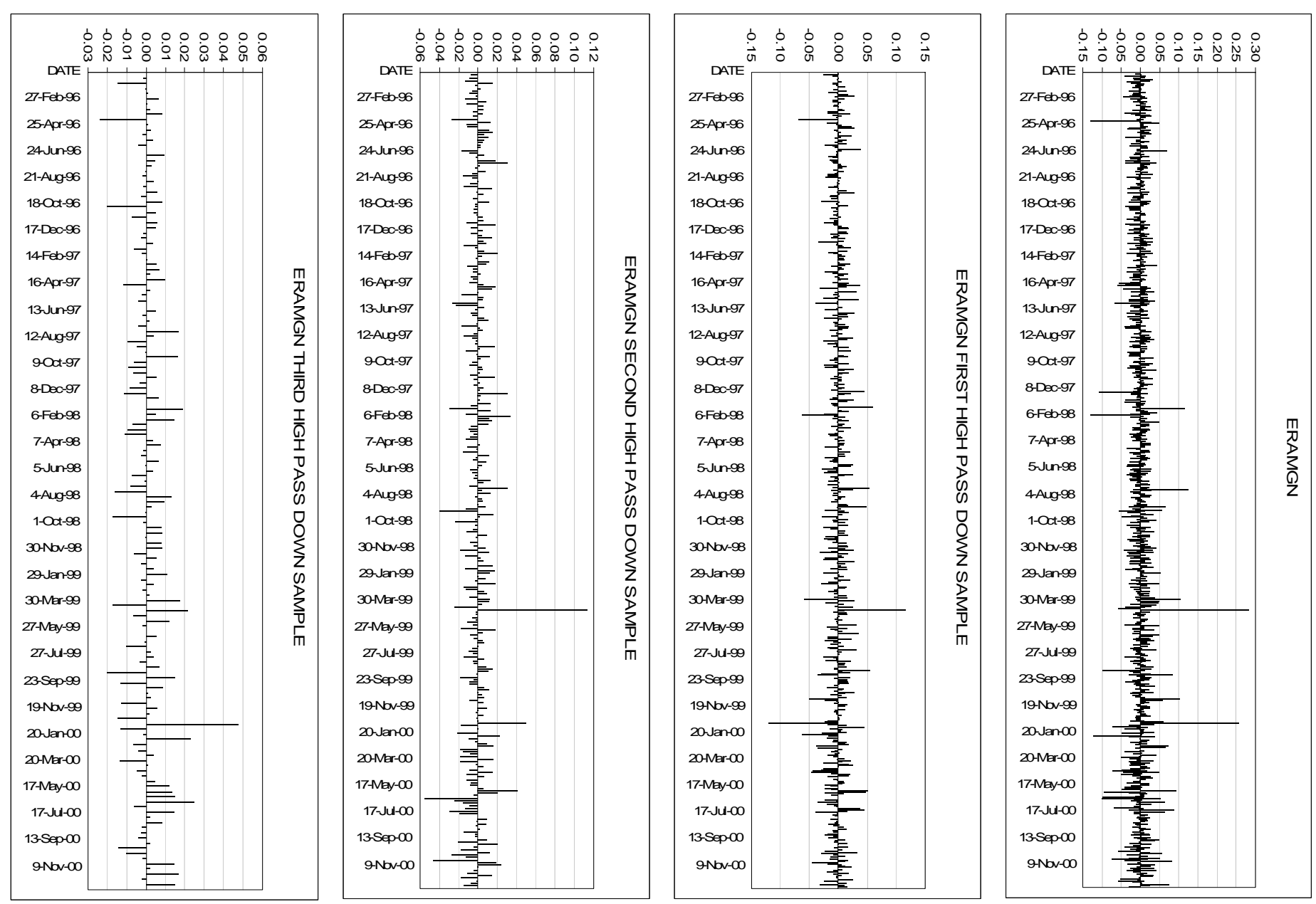

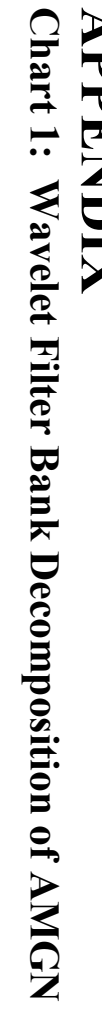



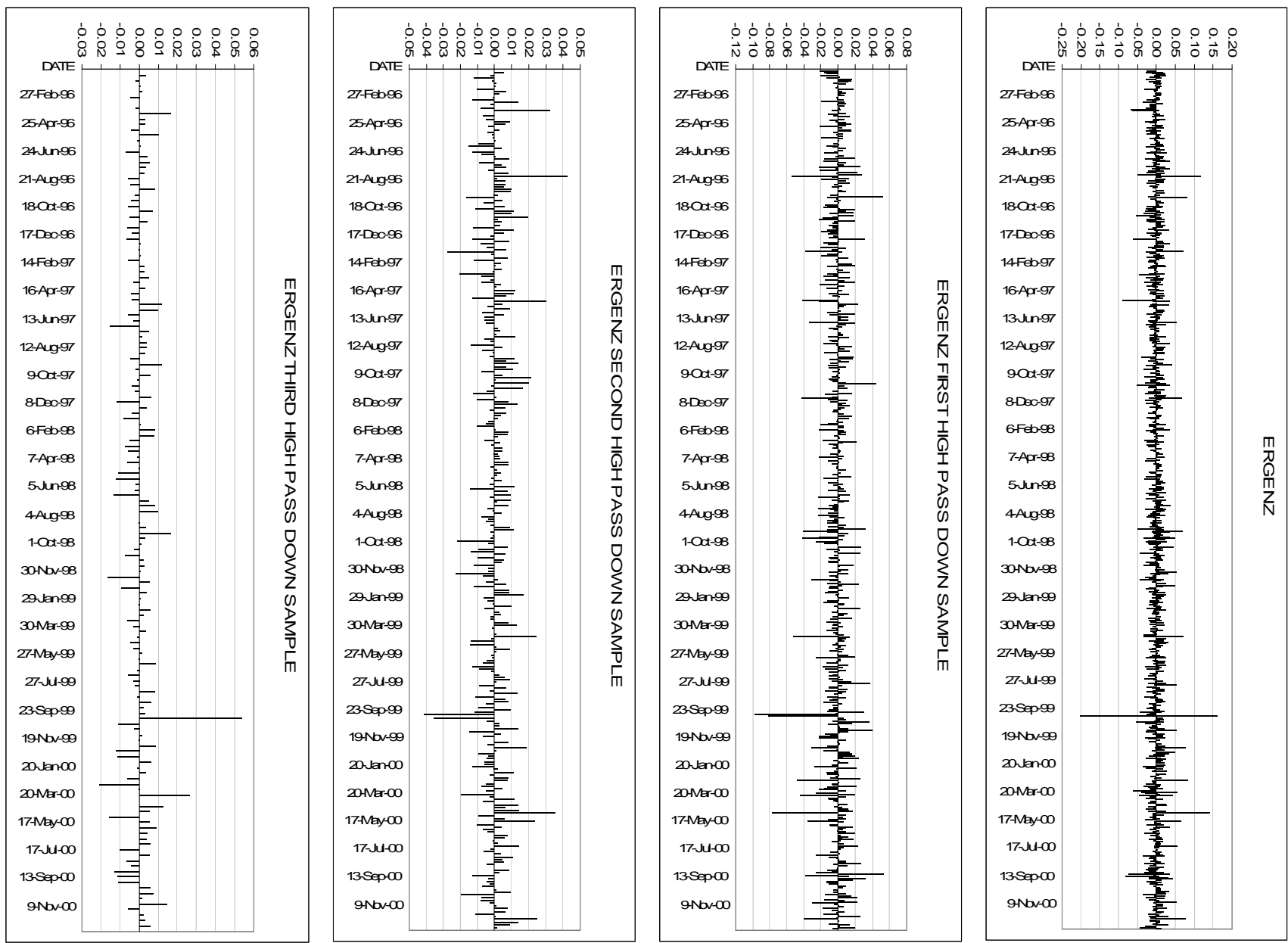

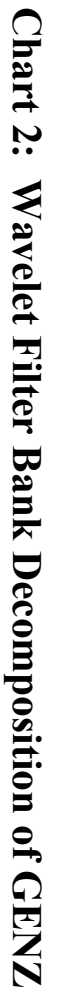


Journal of Global Strategic Management | V. 7 | N. 1 | 2013-June | isma.info | 46-63 | DOI: 10.20460/JGSM.2013715675
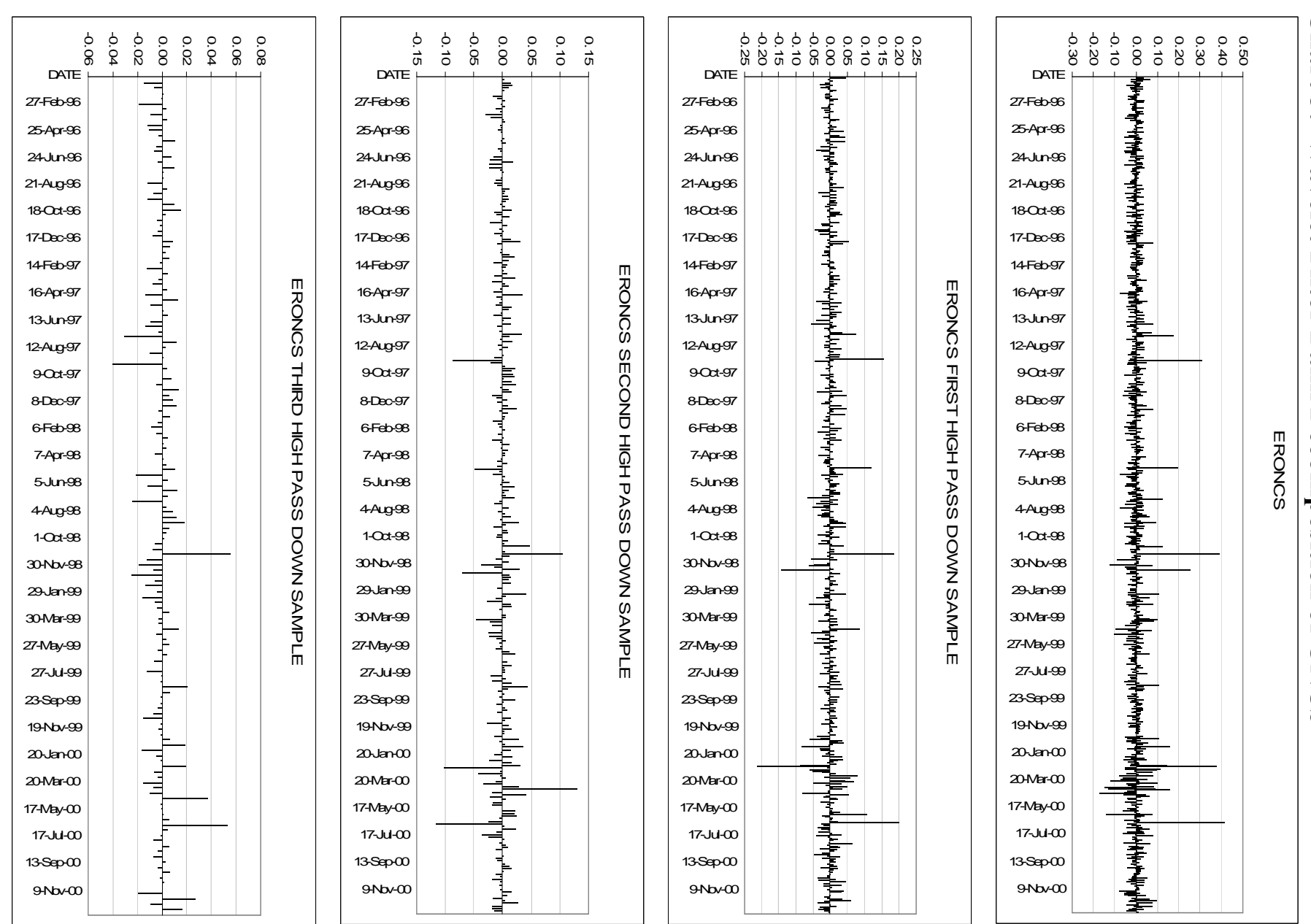

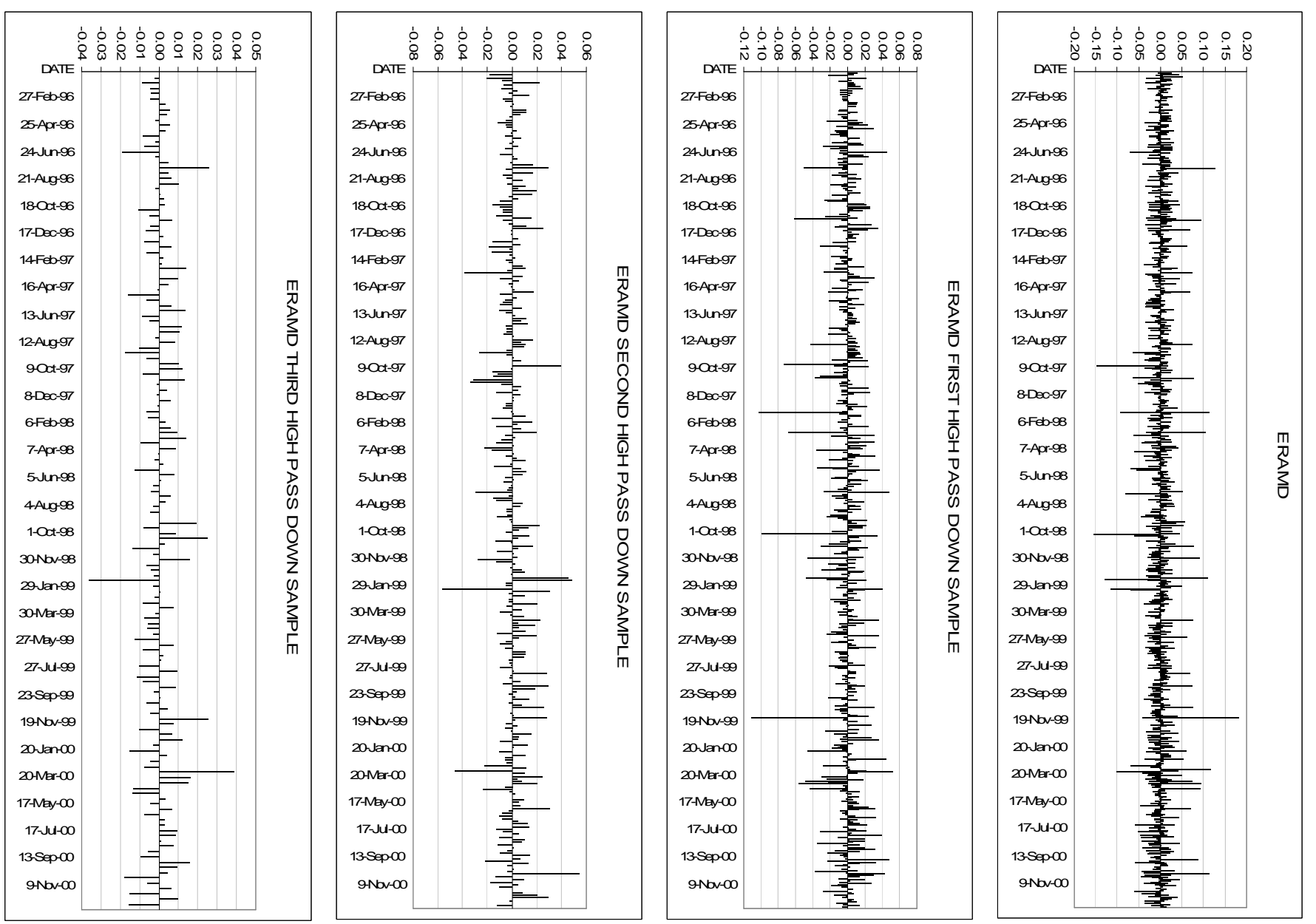

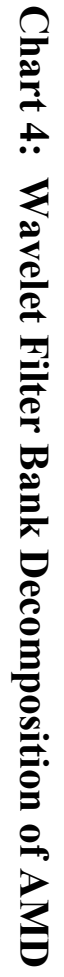



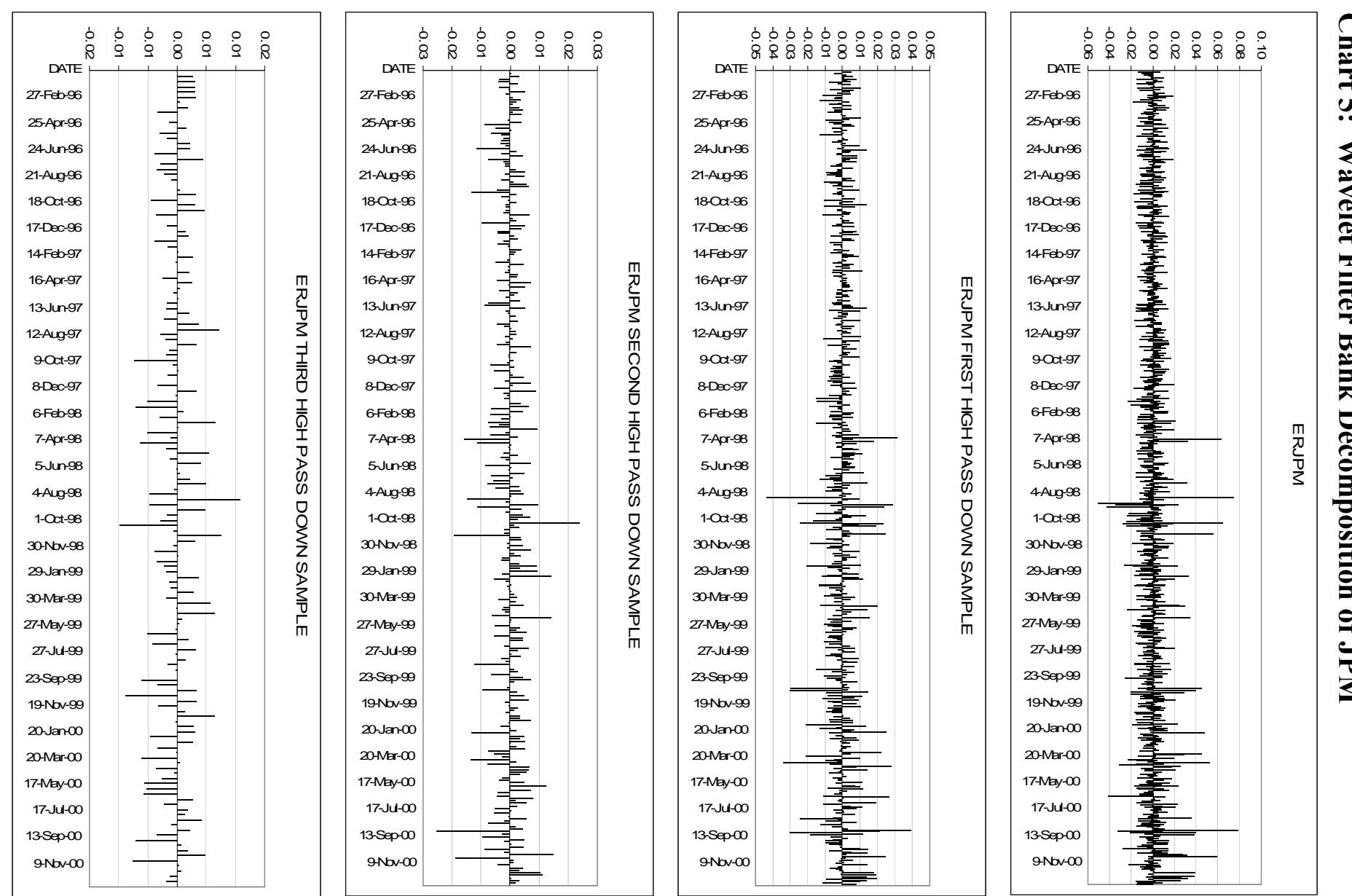

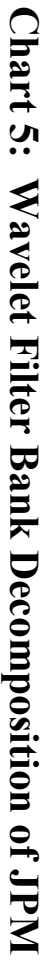



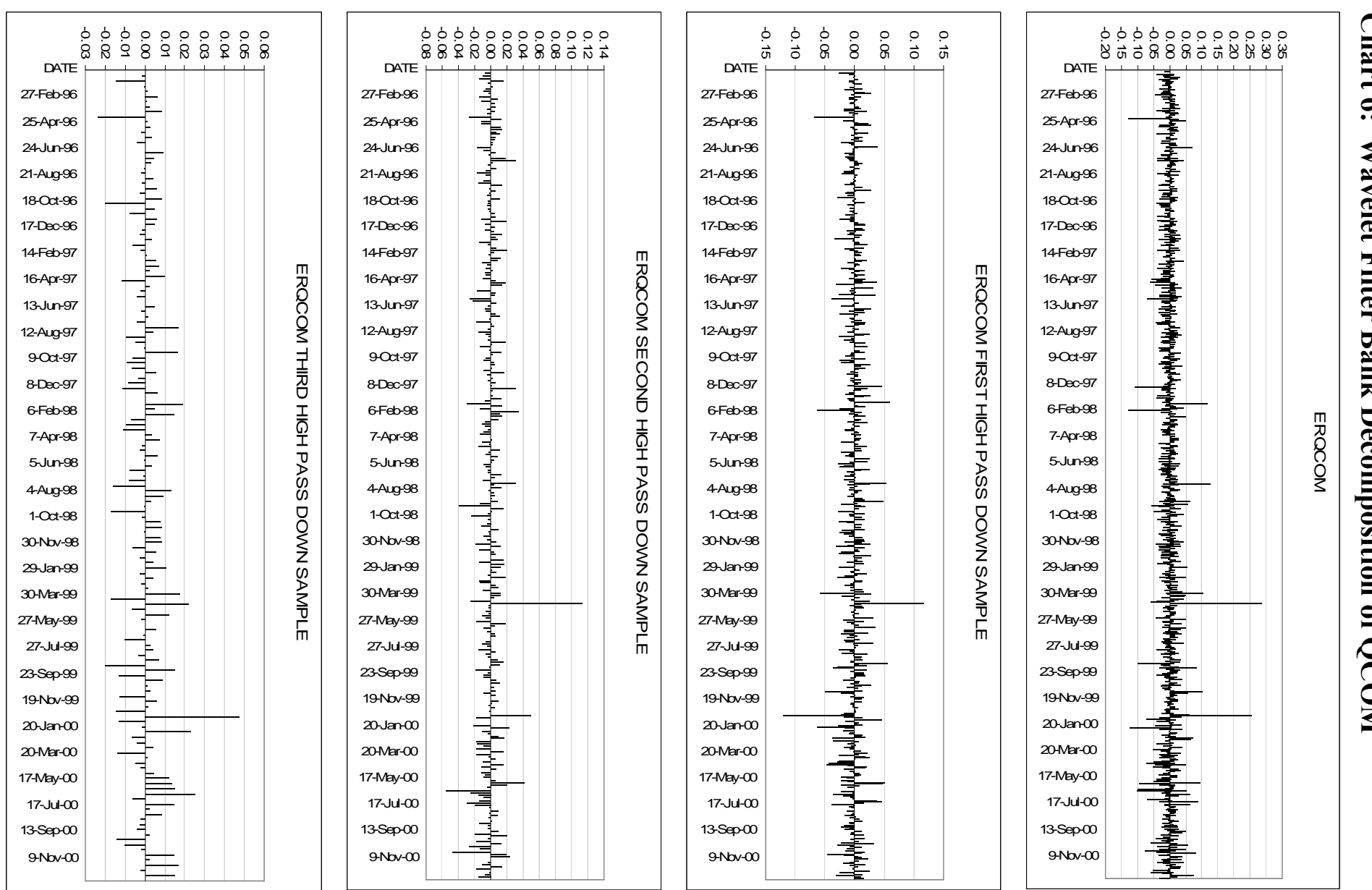

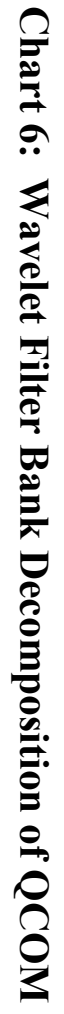



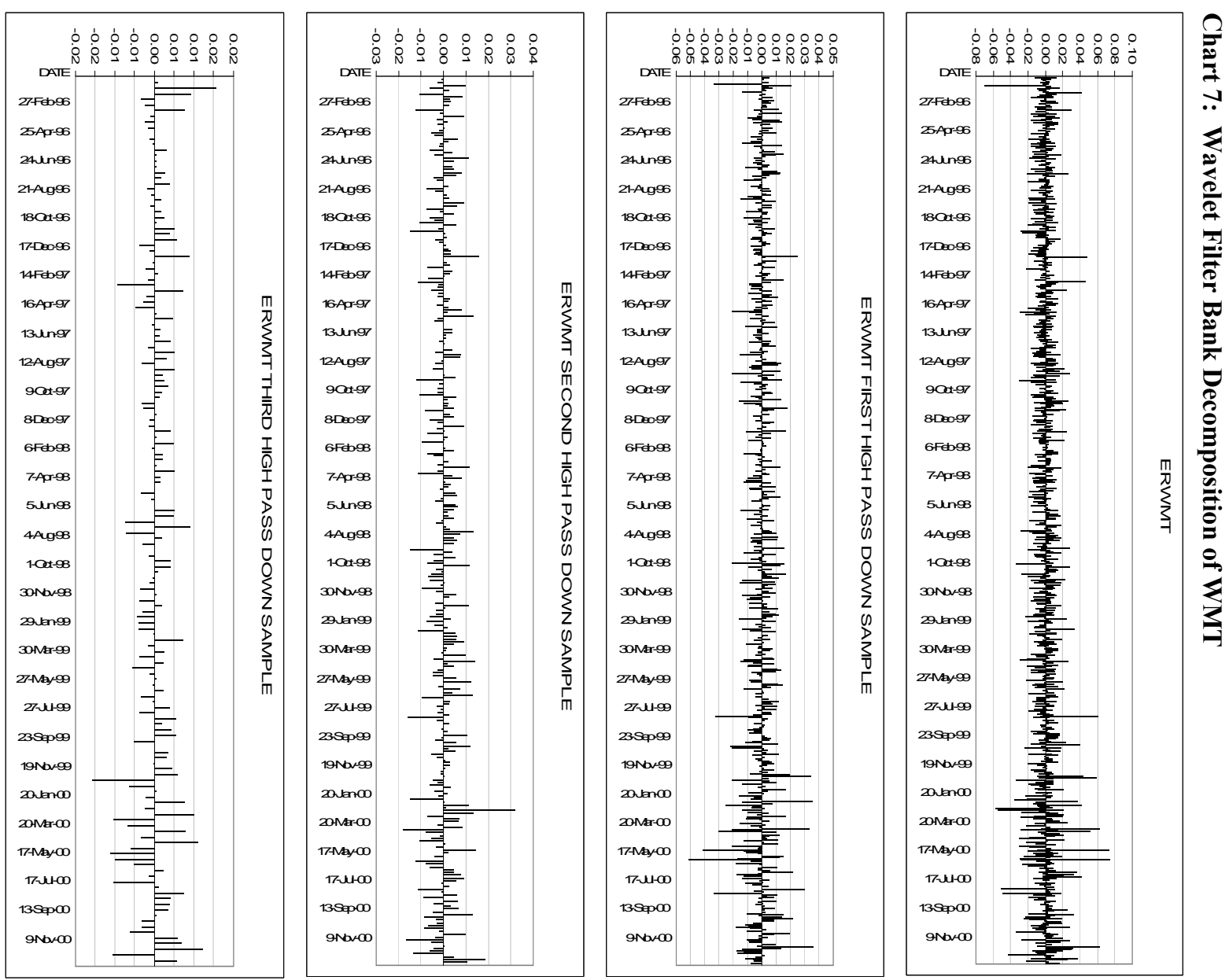

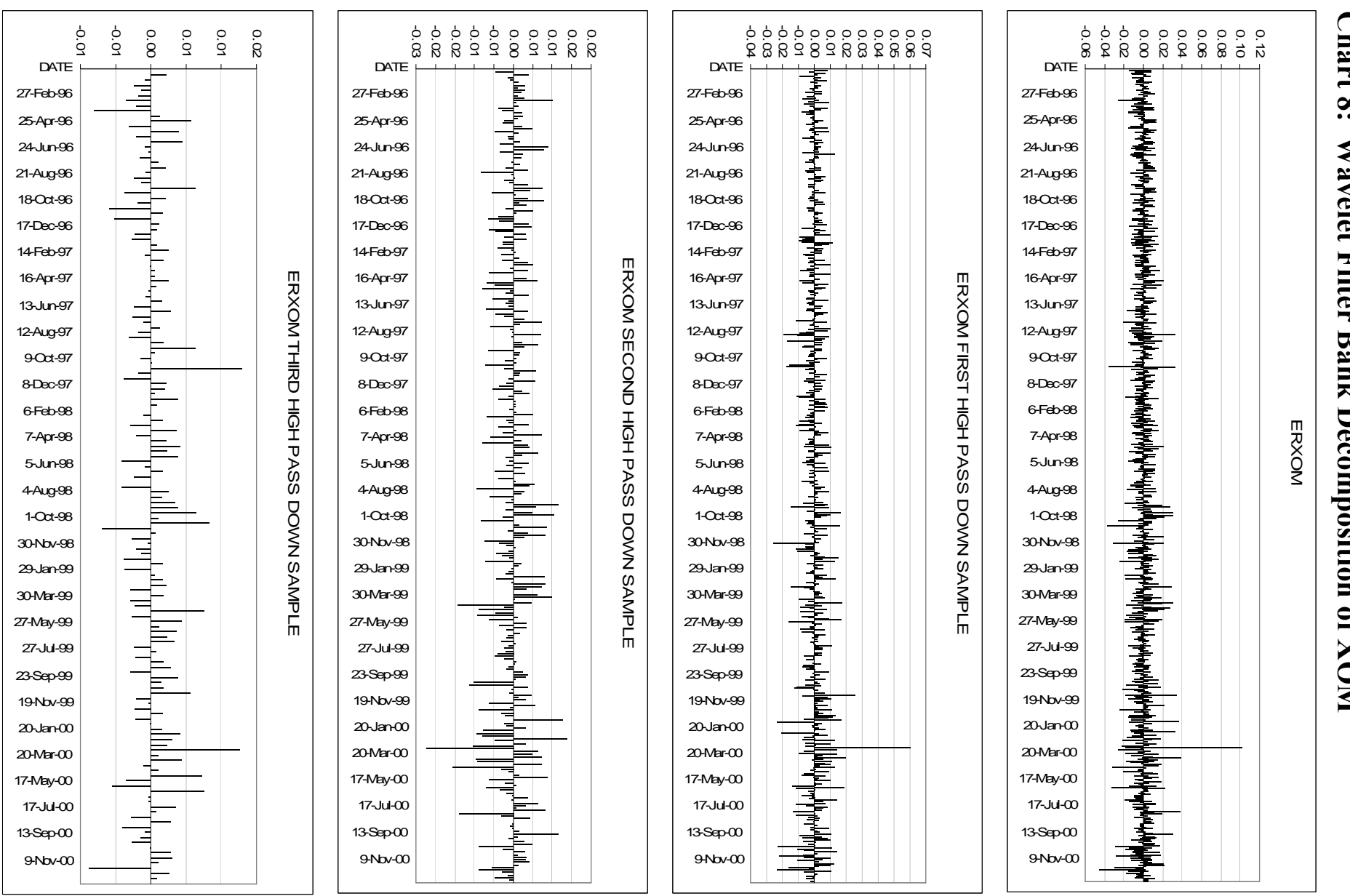

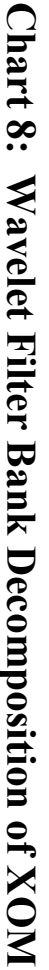




\section{REFERENCES}

Ashley, J., 1962, "Stock Prices and Changes in Earnings and Dividends: Some Empirical Results," Journal of Political Economy, 82-85.

Ball, R., and P. Brown. 1968, “An Empirical Evaluation of Accounting Income Numbers,” Journal of Accounting Research, 159-178.

Barker, C., 1956, “Effective Stock Splits,” Harvard Business Review, 34(1), January-February, 101106.

1957, “Stock Splits in a Bull Market," Harvard Business Review, 35(3), May-June, 72-79.

1958, "Evaluation of Stock Dividends," Harvard Business Review, 36(4), July-August, 99-114.

Bradley, J. N., C. M. Brislawn, et al. (1993). “The FBI Wavelet/Scale Quantization Standard for GreyScale Fingerprint Image Compression.” SPIE Proceedings, Visual Information Process 2.

Brown, S., and J. Warner, 1980, "Measuring Security Price Performance," Journal of Financial Economics, 8, 205-258.

,1985, "Using Daily Stock Returns: The Case of Event Studies," Journal of Financial Economics, 14, 3-31.

Campbell, J., Lo, A., and MacKinlay, J., (1997) Econometrics of Financial Markets, Princeton University Press.

Dolley, J., 1933, “Characteristics and Procedure of Common Stock Split-Ups," Harvard Business Review, 316-326

Donoho, D. L. (1993), "Nonlinear wavelet methods for recovery of signals, densities, and spectra from indirect and noisy data." American Mathematical Society 47: 173-205.

Donoho, D. L. and I. M. Johnstone (1995), "Wavelet Shrinkage: Asymptopia.” Journal of the Royal Statistical Society 57(2): 301-369.

Donoho, D. L. and I. M. Johnstone (1998), “Minimax Estimation via Wavelet Shrinkage.” The Annals of Statistics 26(3): 879-921.

Fama, E., L. Fisher, M. Jensen, and R. Roll, 1969, “The Adjustment of Stock Prices to New Information," International Economic Review, 10, 1-21.

Gabor, D. (1946) "Theory of Communication”, Journal of the Institute of Electrical Engineering, 93(3): 429-457.

Graps, A. (1995), “An Introduction to Wavelets.” IEEE Computational Science and Engineering, 2(2).

Howe T., Pope R., 1996,"Outlier Testing: An Alternative Event Study Methodology," Journal of Economics and Finance, 20, 77-85

Hubbard, B. B. (1998), The World According to Wavelets, $2^{\text {nd }}$ ed. A. K. Peters, Natick, MA.

Meyer, Y. (1993). Wavelets: Algorithms and Applications. Philadelphia, Society for Industrial and Applied Mathematics.

Myers, J., and A. Bakay, 1948, "Influence of Stock Split-Ups on Market Price," Harvard Business Review, 251-265.

Norsworthy, J. R., W. Bessler, R. Schuler, I. W. Morgan, R. Gorener and D. Li (2002) "Asset Pricing and (Some Aspects of) Prospect Theory" working paper, Center for Financial Technology, Lally School of Management and Technology, Rensselaer Polytechnic Institute, Troy NY 12180, USA> 
Norsworthy, J. R., D. Li and R. Gorener, (2000) "Wavelet-Based Analysis of Time Series: An Export from Engineering to Finance." Leading Technology Change: Management Issues and Challenges, Proceedings of the IEEE Engineering Management Society, Albuquerque, NM. pp. 126-132.

Ramsey, J. B. and C. Lampart (1998). "Decomposition of Economic Relationships by Timescale Using Wavelets." Macroeconomic Dynamics 2: 49-71.

Ramsey, J.B. and C. Lampart (1998). "The Decomposition of Economic Relationships by Time Scale Using Wavelets: Expenditure and Income.” Studies in Nonlinear Dynamics and Econometrics, 3(4): $23-42$.

Ramsey, J.B. and Z. Zhang (1997). "The Analysis of Foreign Exchange Data Using Waveform Dictionaries.” Journal of Empirical Finance 4: 341-372. 